\title{
Challenges and Developments in the Utilization of Fly Ash in China
}

\author{
Shu-Hua Ma, Min-Di Xu, Qiqige, Xiao-Hui Wang, and Xiao Zhou
}

\begin{abstract}
China's coal-fired power plants produce about 600 million tons fly ash annually, which has caused severe economic and environmental problems. This paper first describes briefly the production and utilization status of coal fly ash in China. Then it analyzes the main challenges to the fly ash utilization in China due to the conflict between the huge amount production of fly ash and the depressed consumption of fly ash, as well as the increasing driving forces in the environmental protection. Subsequently, the new developments of fly ash utilization in China, including valuable elements extraction, geopolymer production, fly ash-based ceramics synthesis and soil desertification control are introduced in detail.
\end{abstract}

Index Terms - Fly ash, utilization, challenge, development.

\section{INTRODUCTION}

Coal fly ash (CFA), a solid residue produced in the coal-fired power plants, has been the largest quantity of industrial solid waste in China. Now its annual output is estimated to be around 600 million tons (Mt). Because of the lack of effective consumption ways, 200 million tons fly ash has to be stored up every year [1]. As a result, the total accumulation may reach the level of $\sim 3$ billion tons, a very terrible value. China's high CFA output is decided by the Chinese energy structure. It is reported that coal accounts for $62 \%$ of China's primary energy consumption [2], which is far more than the world average level. Moreover, although China has greatly developed other type of energy, such as wind energy, solar energy and water energy, the coal ratio in the Chinese energy structure can't decrease effectively in the near future.

As is well known, CFA's composition is very complex. CFA contains several common elements including $\mathrm{Si}, \mathrm{Al}, \mathrm{Ca}$, and $\mathrm{Fe}$, etc. and it also contains some toxic metals such as $\mathrm{Cr}$, $\mathrm{Hg}$, $\mathrm{As}$ and $\mathrm{Pb}$, which greatly degrade the soil and enhance the air and water pollution, and ultimately affect the human health [3]. Besides, CFA is an ultrafine solid residue, some of which inevitably enters into atmosphere with wind. Usually fly ash can deposit in the nearby several decades $\mathrm{km}$ or farther environments of the coal-fired power plants. It has been thereof one of the primary sources of particle pollutions

Manuscript received August 19, 2017; revised October 13, 2017.

Shu-Hua Ma and Xiao-Hui Wang are with the National Engineering Laboratory for Hydrometallurgical Cleaner Production Technology, Key Laboratory of Green Process and Engineering, Institute of Process Engineering, Chinese Academy of Sciences, Beijing, China (e-mail: shma@ipe.ac.cn).

Min-Di Xu is with the Dufar (Pingyuan) Technology Co. Ltd., Dezhou, China.

Qiqige and Xiao Zhou are with the Xilingol Professional College, Xilinhot, China. in the west and north of China.

So, CFA utilization is seriously emphasized in China. It is gratifying that it has made great progress, and several effective and profitable comprehensive utilization methods have shown a promising prospect, although it is facing huge challenges. This paper will give an insight into the CFA utilization in China. It will first introduce the current status of CFA production and utilization in China, providing a historical perspective on the fly ash utilization ways developed. Then, it will analyze the challenges to the CFA utilization due to the conflict between the huge amount production of CFA and the depressed consumption of CFA, as well as the increasing driving forces in environment protection, exhibiting a sober and responsible analysis on the situation of CFA utilization. Finally, the development trends of CFA utilization in China, including alumina extraction (only for the high-alumina fly ash), geopolymer, fly ash-based ceramics and soil desertification treatment, etc., will be discussed in detail, offering a relative clear guidance for future initiatives on CFA utilization. This paper will prove helpful to the researchers interested in environmental protection, ecological construction and health evaluation for background information.

\section{ANALYSIS ON THE CURRENT Status OF CFA PRODUCTION AND UTILIZATION}

\section{A. A Brief Description of CFA Production}

China's energy structure takes coal as a leading resource. And in the future 20-30 years, China will still maintain the coal-based energy structure to meet its fast development of national economy. With the increasing consumption of coal, the emissions of CFA from coal-fired power plants have become the largest industrial solid waste in China. Fig. 1 shows the generation of CFA in China from 2006 to 2015 [4]. Annual CFA generation is still increasing and has already reached $\sim 600 \mathrm{Mt}$ by 2015 . Although there is still no accurate statistics for the next future years, the figure is thought to grow further slowly and the output of CFA will remain the level of 600 620 Mt.

The environmental impact of fly ash is now being fully recognized, as impels us continuously to increase the utilization rate of fly ash in China greatly, which has reached a higher level of $70 \%$ in 2015 compared to rates of $20 \%$ in 1999 and $14 \%$ in 1980. This rate is equal to the expected level in The China's 12th Five-year Plan for the bulk industrial solid waste comprehensive utilization. But if the CFA utilization rate in China can continue to increase by the last decade's level is quite difficult to be determined. In the future, CFA utilization will face several great challenges. The 
reasons for that will discuss in the following section of this paper.

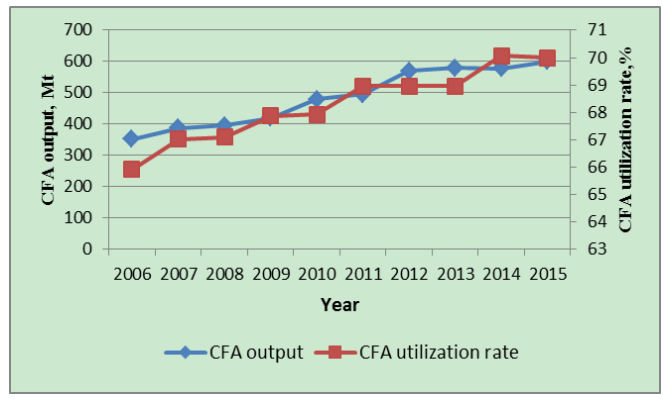

Fig. 1. The CFA generation and its utilization rate in China.

\section{B. A Brief Description of CFA Utilization}

Because of the huge quantity of CFA production and the potential environmental risk, Chinese government has always attached high importance to CFA utilization. It adopted a range of major policy measures to strengthen this project and encouraged to develop a series of technologies to produce high-blending cement, CFA concrete, aerated concrete products, etc. to promote the capacities of CFA utilization in a large scale.

Fig. 2 illustrates the utilization situation of CFA in China in 2013. Same as the CFA utilization ways in majority of other countries, CFA utilization in China concentrates in the fields of cement, concrete and new style wall materials, accounting for near $90 \%$ of the total CFA consumption. Since the 1950s, CFA had started to be used as an additive in cement and concrete. When using as an additive in cement, CFA can replace some of clay or other silica- or alumina-containing materials because CFA's composition is very similar to the nature clay. Besides, CFA is also to be used as mixture to blend with clinker owing to its pozzolanic properties. When fly ash is used as a replacement for Portland cement in concrete, it can improve the strength and durability of concrete remarkably. As for the wall materials, CFA can mix with cement, gypsum and clay, etc. to produce autoclaved aerated concrete blocks. Because no high temperature is required, this technique reduces air pollution and decreases energy consumption. So the above utilization ways are very popular in China.

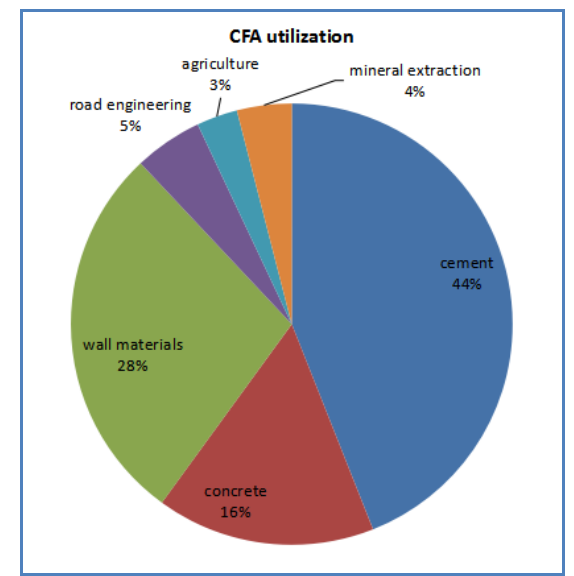

Fig. 2. Illustrates the utilization situation of CFA in China in 2013.

Data source: 2014 Annual Report on Chinese Resource Comprehensive Utilization Situation issued by China National Development and Reform Commission
In addition, there is a little consumption of CFA in the road engineering, agriculture, mineral extraction, etc. occupying $\sim 10 \%$ of the total CFA consumption. In the past several decades, China strengthened the construction of infrastructure and thereof a lot of CFA was consumed. In the agriculture field, in virtue of its special physical properties like water holding capacity, bulk density, $\mathrm{pH}$ etc., and containing almost all the essential plant nutrients, fly ash is used to improve the soil physic-chemical characteristics and increase the output and qualities of the plants [5]. But CFA contains number of toxic heavy metals and also have natural radioactivity materials in it. Therefore, CFA has yet to be used in agriculture in China in a large scale. Its application in agriculture takes up only $3 \%$ of the total consumption. When CFA is considered as a useful and potential mineral resource, it can be applied in the mineral extractions. Many researches and industrial practices have been carried out and mainly focused on alumina extraction. In order to utilize the special high-alumina fly ash produced in the north of China, several methods including limestone sintering process, pre-desilication and lime-soda sintering process, hydro-chemical process, acid process and ammonium sulphate sintering process, etc. have been proposed [6]-[8]. All of these technologies emphasize particularly on the alumina extraction, and they can yet solve the silica synchronous utilization, as easily leading to a second pollution and poor economic benefit. So the consumption in this field makes up a very small proportion as yet, impressed $4 \%$.

\section{Challenges In The CFA Utilizaton}

\section{A. The Deceleration of Real-Estate Industry}

As has shown in the Fig. 2, 90\% CFA consumed in China has primarily been used in the applications in cement, concrete, brick manufacturing and road or dam construction. These applications are very close related to the real-estate industry. In the past twenty years, China's real-estate industry has gone through a very rapid process. As a result of it, per capita living space has changed from $10.3 \mathrm{~m}^{2}$ in 2000 to $40.8 \mathrm{~m}^{2}$ in 2016 [9], a sharp increase. Currently, except several first-tier cities, the proportion of the unoccupied housing is too high in many cities. Therefore, the development speed of real-estate industry will be inevitably slowed down in the near future. Thus, the CFA consumption in the above fields will affected undoubtedly. A rough estimation shows that the CFA consumption in these fields will decrease by at least $\sim 20 \%$.

\section{B. The Regional Unbalance between the Supply and Demand of CFA}

China is a huge country which contains an area of 9.6 million square kilometers. It has many different geographical environments and various level of economic development. For example, the northwest of China is in the arid and semi-arid area, and has a relative lower population density and lower level of economic development. In contrast, the southeast of China is rich in the water resource, where population density is very high and economic development 
levels are more advanced than those of other places in China. These differences lead to the distinct difference in the scale of CFA utilization. The big cities in the southeast area are always the primary CFA consumers in China, where CFA produced in local coal-fired plants has been almost reused, and even the demand of CFA often exceeds its supply. While in the northwest of China were built many coal-fired plants due to its richness in coal resources, where the output of CFA is remarkable, but the CFA utilization rate is rather low, causing a huge amount of accumulation. Nevertheless, long transportation cost between the above areas seriously restricts the CFA produced in the northwest consumed by the southeast areas. More seriously, the newly-built coal-fired plants in the recent years will all be located in the northwest. How to utilize these fly ashes effectively will be a big challenge.

\section{Increasing Driving Forces in Environmental Protection}

China's rapid economic development combined with backward environmental management has caused a number of ecological problems. In order to improve the environmental situation, China's government has undertaken a number of measures to curb pollution in China. For example, in recent five years it issued a series of regulations and laws, including Action Plan of Prevention and Control of Air Pollution (issued on Sep. 12, 2013), Water Pollution Prevention \& Control Action Plan (issued on Apr. 2, 2015), Action Plan on Prevention and Control of Soil Pollution (issued on May 28, 2016), Environmental Protection Tax Law of the People's Republic of China(issued on Dec. 25, 2016), etc. to better fight pollution. Besides these, several special measures with regard to the CFA utilization, such as Management Measures for Comprehensive Utilization of Fly Ash (issued on Jan. 5 in 2013) and Coal Clean \& Efficient Utilization Action Plan (2015-2020) (issued on Apr. 27, 2015), were released. At the same time, a state-level environmental protection supervision team was established on Jan. 4, 2016. The team works to urge the provincial and city governments to carry out anti-pollution measures and help handle problems involving variable pollution. Government leaders will be punished if they can't finish their environmental-protection tasks or are involved in related misconduct on the job. In addition, public awareness in the environmental protection has been raised greatly under the guidance of the China's government. All of the above driving forces suggest that solid waste like CFA must be found a way out as soon as possible.

\section{DEVELOPMENT IN THE CFA UTILIZATION}

Owe to the above several challenges to the CFA in China, it is very necessary to expand its utilization fields and technologies. During the past few years, some researchers have tried to recycle CFA for preparing industrial minerals or agricultural products, completely different from the conventional building materials. Here will introduce these new developments of CFA utilization in China.

\section{A. Valuable Elements Extraction}

The development of high value-added utilization technologies of fly ash is quite important in terms of increasing potential profit. One decade ago, a new type of fly ash called high alumina fly ash (HAFA) was discovered in the northwest of China. Due to its high alumina content $(\sim 50 \%)$, HAFA can be seen as a kind of potential raw material for extracting alumina to increase the effective supply of aluminum-containing resources since $\sim 45 \%$ bauxite in China, the world's main source of aluminium, is dependent upon import. Therefore, recovering aluminum from HAFA has been paid great attention. Up to date, several methods including limestone sintering process, pre-desilication and lime-soda sintering process, hydro-chemical process, acid process and ammonium sulphate sintering process, etc. have been proposed. But only pre-desilication and lime-soda sintering process was gone into the stable industrial applications in a large scale. The others had to stop for some reasons. Now recovering alumina from HAFA is focused on two aspects, one is to make further efforts to improve the above processes, and the other is to study the utilization of silica in the fly ash deeply. Several silica products such as zeolite, calcium silicate heat-insulating board, paper filler, etc. have been developed successfully [10], [11]. But the utilization of dicalcium silicate $\left(2 \mathrm{CaO} \cdot \mathrm{SiO}_{2}\right)$ residues have yet be solved completely because of their high water content and complex compositions, which will be one of the future research plans. In addition, the extraction of other elements including gallium, germanium and even lithium are becoming research hot topic [12]-[14]. These contents have been listed in the China's major research plans in the Thirteenth Five period.

\section{B. Fly Ash-Based Ceramics Synthesis}

Due to the developing of urbanization, China's building ceramic industries have developed rapidly, and the ceramic tile production has ranked first in the world in more than ten years. With the expanding of ceramic industries, the traditional ceramic raw materials such as kaoline, feldspar, etc. become deficient day by day, and the lack of raw materials has restricted the sustainable development of the ceramic industries. CFA, as a kind of aluminum-silicate system material, has a very high similarity with the ceramic materials in the terms of chemical and phase compositions. Consequently, applying CFA as a substitute for the traditional ceramic raw materials in the ceramic production is of great significance. But the present utilization of CFA is too simple and straightforward in ceramic fields [15], [16]. As a result, the mass ratio of $\mathrm{CFA}$ in the raw materials for ceramics production is less than $20 \%$. Now a research team from Institute of Process Engineering, Chinese Academy of Sciences is changing this situation. It found that CFA with a different average particle size has a different mineralogical composition. Thus by exploring the basic properties of CFA particles with different sizes and their different roles in ceramic bodies, they established a new technology to produce a kind of total-fly ash ceramics with all properties better than the nation's standards [17]-[19].

\section{Geopolymer Production}

The name of Geopolymer was first proposed by an French 
professor in 1978, which is a kind of inorganic compounds containing $\mathrm{AlO}_{4}$ and $\mathrm{SiO}_{4}$ connected each other in a hollow net structure. It is characterized by good mechanic properties, high strength on the early stage, excellent absorption capacities for almost all toxic metal ions, low energy consumption and carbon dioxide emission, etc. So it is popular in engineering application. Presently, this new polymer has been being studied in the special research institutes in more 30 countries all over the world and some products have gone into actual applications [20]. In China, it has gradually been a hot point to synthesize geopolymer by using fly ash as main raw materials in the last several years [21]. To promote the improvement of this technology, a non-authorized academic organization named fly ash geopolymer speciality committee was built half a year ago. Now the research contents mainly focus on the effect of fly ash activators kind and quantity and curing process on the material properties, as well as the aggregation mechanism of key ion clusters $\mathrm{AlO}_{4}$ and $\mathrm{SiO}_{4}$. Great progresses have been made in this field [22]. However, the higher cost of this product comparing to the cement product has not solved yet. Moreover, if alkali aggregate reaction occurs during the application of geopolymer, and if yes, how to avoid it remains unknown.

\section{Soil Desertification Control}

The northwest of China is one of Chinese important coal production and electric generation bases, where accumulated a large amount of CFA. It is in the arid and semi-arid area, where water resource shortage is very serious. For example, in Xilingol League, Inner Mongolia, the annual rainfall is only 150-350 mm, but annual evaporation reaches the high value of $2000-2700 \mathrm{~mm}$, as leads to the typical ecological environmental problems such as grassland degradation, land salinization and soil desertification, etc. So, ecological environment in the areas like Xilingol League is facing a severe challenge.

To address the crisis of above ecological problems as well as the CFA utilization problems, many studies have been carried out in China [23], [24]. Currently, developing water-retaining products and activating the useful elements in CFA are two research hot topics among of these studies. Although super absorbent resins, such as starch grafting acrylic acid or cellulose graft co-polymer, have been developed well. But they are not cheap and/or biocompatible, as limits their applications in the soil remediation in a large scale. In contract, inorganic water-retaining product is more popular due to its lower production cost and better biocompatibility. But CFA does not contain enough water-absorbing hydroxyls on the surface of the clay-like mineral. So the water-retaining property of original CFA is not ideal. Moreover, as a by-product under the condition of high temperature, CFA contains many inactive nutrient elements. To solve these problems, a CFA expansion utilization as a new soil desertification control product was developed. This new product has a near $90 \%$ porosity, and thereof it can absorb water as much as 4 9 times of its own weigh. When it is put with $4 \%$ weight of the normal soil under the normal soil with $15 \mathrm{~cm}$ thick, the water-retaining time of the soil can reach the surprising level of 48 days in an indoor laboratory with the temperature of $15-20{ }^{\circ} \mathrm{C}$ and humidity of $40 \% \sim 60 \%$. Moreover, the product contains more than $30 \%$ active silicon, far higher than the $3 \%$ of the original CFA. So it is believed that this CFA application will developed very well in the special geological area.

\section{Conclusions}

China' continuous development at a high speed consumed huge amount of coal and also produced huge amount of CFA. During the current period of economy transformation, CFA utilization in China is facing severe challenges primarily due to the deceleration in real-estate industry, the regional unbalance between the supply and demand of CFA, more and more strong driving forces in the environmental protection. To solve the CFA utilization, some new technologies have been developed in China. The representative technologies including valuable elements extraction, fly ash-based ceramics production, geopolymer synthesis and soil desertification control have showed a promising prospect.

\section{REFERENCES}

[1] National Development and Reform Commission of China, Annual Report on China's Resource Comprehensive Utilization (2014), 2014, Beijing.

[2] Ministry of Environmental Protections of the People's Republic of China, 2016 China's Environmental Situation Communique, 2017, Beijing.

[3] P. Chindaprasirt, C. Jaturapitakkul, and T. Sinsiri, "Effect of fly ash fineness on microstructure of blended cement paste," Construction and Building Materials, 2007, vol. 21, no. 7, pp. 1534-1541.

[4] Y. S. Cui, X. H. Wu, and P. Yuan, "China's fly ash production, utilization and development (in Chinese)," presented at 2015 International Communication Conference on Asia Fly Ash and Desulphurization Gypsum Comprehensive Utilization Technologies, 2015, Shuozhou, Shanxi Province.

[5] S. M. Shaheen, P. S. Hooda, and C. D. Tsadilas, "Opportunities and challenges in the use of coal fly ash for soil improvements - A review," Journal of Environmental Management, 2014, vol. 145, pp. 249-267.

[6] Q. C. Yang, S. H. Ma, H. Xie, and S. L. Zheng, "Research progress of extracting alumina from high-aluminum fly ash," Multipurpose Utilization of Mineral Resources, 2012, vol. 3, pp. 3-7.

[7] S.-F. Dai et al., "Abundances and distribution of mnerals and elements in high-alumina coal fly ash from the Jungar Power Plant, Inner Mongolia, China," International Journal of Coal Geology, 2010, vol. 81, pp. 320-332.

[8] J. Ding, S.-H. Ma et al., "Research and industrialization progress of alumina recovery from fly ash: a concise review," Waste Management, 2017, vol. 60, pp. 375-387.

[9] Natioal Bureau of Statistics of the People's Republic of China, The residents income is increasing constantly and the people's life quality is improved continuously - The seventh report on the economic and society development achievement since the 18th National Congress of the Communist Party of China.

[10] X.-T. Liu et al., "Study of preparation process optimization of calcium silicate board by using JMP (In Chinese)," New Building Materials, 2015, vol. 1, pp. 83-86.

[11] Y.-M. Fan, "Study on Application of Fly Ash and Fly Ash Fibre in Papermaking (in Chinese) [D]," Northeast Forestry University, 2012, Haerbin.

[12] H.-D. Liu et al., "Rare elements gallium, niobium and rare earth elements combined extraction from fly ash (in Chinese)," Science and Technology Guide, 2015, vol. 33, no. 11, pp. 39-43.

[13] X.-Q. Hou et al., "Leaching of lithium from fly ash using caronate (in Chinese)," Journal of Hebei University of Engineering (Natural Science Edition), 2015, vol. 32, no. 1, pp. 58-61.

[14] M.-Y. Jin et al., "Extraction gemanium from gemanium- containing fly ash by reduction and evaporation method (in Chinese)," Nonferrous Metals (Extractive Metallurgy), 2015, vol. 3, pp. 50-53.

[15] J. Liu et al., "Feasible recycling of industrial waste coal fly ash for preparation of anorthite-cordierite based porous ceramic membrane 
supports with addition of dolomite," Journal of the European Ceramic Society, 2016, vol. 36, no. 4, pp. 1059-1071.

[16] R. Ji et al., "Preparation of novel ceramic tiles with high $\mathrm{Al}_{2} \mathrm{O}_{3}$ content derived from coal fly ash," Construction and Building Materials, 2016 , vol. 114, pp. 888-895.

[17] Y. Luo et al., "Preparation and characterization of whisker- reinforced ceramics from coal fly ash," Ceramics International, 2017, vol. 43, pp. $1-11$

[18] Y. Luo et al., "Effect of particle size and alkali activation on coal fly ash and their role in sintered ceramic tiles," Journal of the European Ceramic Society, 2017, vol. 37, no. 4, pp. 1847-1856.

[19] Y. Luo et al., "Ceramic tiles derived from coal fly ash: Preparation and mechanical characterization," Ceramics International, 2017, vol. 43, pp. 11953-11966.

[20] N. Toniolo and A. R. Boccaccini, "Fly ash-based geopolymer containging added silicate waste. A review," Ceramics International, 2017.

[21] H. Xu et al., "Synthesis of thermostable geopolymer from circulating fluidized bed combustion (CFBC) bottom ashes," Journal of Hazardous Materials, 2010, vol. 175, pp. 198-204.

[22] T. Yang, H.-J. Zhu, and Z.-H. Zhang, "Influence of fly ash on the pore structure and shrinkage characteristics of metakaolin-based geopolymer pastes and mortars," Construction and Building Materials, 2017, vol. 153 , pp. 284-293.

[23] H.-H. He, Z.-G. Dong, Q. Peng et al., "Impacts of coal fly ash on plant growth and accumulation of essential nutrients and trace elements by alfalfa (Medicago sativa) grown in a loessial soil," Journal of Environmental Management, 2017, vol. 197, pp. 428-439.

[24] J. Zhao, Z.-Z. Kang, Q.-Q. Han et al., "The application and prospect of fly ash in soil improvement and remediation (in Chinese)," Jiangsu Agriculture Sciences, 2017, vol. 45, no. 2, pp. 1-5.
Shu-Hua Ma was born in January 1970. She received the Ph.D. degree from Institute of Process Engineering, Chinese Academy of Sciences (IPE-CAS), Beijing, China. Currently, she is a professor with the IPE-CAS. She has published many articles about the utilization of CFA. Her research interests are all concerned with the utilization of solid waste, especially the CFA utilization.

Min-Di Xu a famous National "Thousand People Plan" Specially-invited Expert (2012), received his Ph.D degree from University of Cincinnati, USA Now he is the president and director of Dufar (Pingyuan) Technology Ltd Co. China. His research interests focus on the developments of new materials.

Qiqige is the director of the Institute of Lignite Fly Ash Engineering and Technology, Xilingol Professional College, Xilinhot, China. She has engaged herself in the research on lignite fly ash utilization and developed many feasible fly ash utilization technologies with her co-workers. Specially, she and her team have made great progress in the soil amendment by adding the activated fly ash.

Xiao-Hui Wang was born in June 1980. He received the Ph.D. degree from Institute of Process Engineering, Chinese Academy of Sciences (IPE-CAS), Beijing, China. Currently, he is an associate professor with the IPE-CAS. His research interests include utilization of CFA and rare metal solid waste.

Xiao Zhou was born in January 1990. He received the master's degree in 2015 from Beijing University of Chemical Technology, Beijing, China Currently, he is an assistant teacher with Xilingol Professional College, Xilinhot, China. And he is also a researcher of the Institute of Lignite Fly Ash Engineering and Technology, Xilingol Professional College. His research interest is comprehensive utilization of fly ash. 